\title{
Editorial: Seismic Analysis and Retrofitting of Historical Buildings
}

\author{
Antonio Formisano ${ }^{1}$ and Michele D'Amato ${ }^{2 *}$ \\ ${ }^{1}$ Department of Structures for Engineering and Architecture, University of Naples Federico II, Naples, Italy, ${ }^{2}$ Department of \\ European and Mediterranean Cultures, University of Basilicata, Matera, Italy
}

Keywords: cultural heritage, modeling, interventions, seismic analysis, structural diagnosis

\section{Editorial on the Research Topic}

\section{Seismic Analysis and Retrofitting of Historical Buildings}

The proposed Special Issue has been addressed to conservation and protection of historical buildings with respect to the seismic action. It provides an overview of recent advances aimed for territorial and local evaluations of seismic performance of existing constructions having also historical value, either in masonry or in concrete. As for the methods applied at a territorial scale, essentially consisting of fast appraisal methods providing a score (or index) which are only based on qualitative evaluations, it is clearly pointed out that they may not substitute more refined and specific numerical models. They are only capable of quickly screening constructions in a certain area, and of individuating the priorities to be investigated in depth with more appropriate numerical investigations. As far as the application of these numerical models is concerned, different approaches may be followed in order to design adequate interventions capable of upgrading a construction up to a safety level of a newly constructed building. As highlighted within the manuscripts submitted, the knowledge requires acquisition of construction and geometrical details, including existing crack patterns, even before of materials properties. Moreover, the data acquisition should be done in an incremental and adaptive way with updated numerical models, for permitting of highlighting those parameters that considerably influence the seismic response. In this way, the invasiveness of the in-situ experimental tests is minimized, also from an economical point of view.

In the manuscript proposed by Chieffo and Formisano three different methods, coherent with a multi-level approach, are applied for seismic assessment of masonry buildings aggregates. The authors remark the importance of using appropriate numerical models, since territorial methods are not able in specifically predicting the seismic performance of a construction.

In Chiumento and Formisano, a preliminary seismic vulnerability assessment through a fast appraisal method is applied. The plan distribution influence of structural units belonging to the same masonry cluster is investigated. To this scope the lateral response of some independent structural units is compared with the global one, evaluated with non-linear pushover analyses. The comparisons reported show that isolated structural units have lower stiffness and strength than the ones calculated by referring to the entire compound.

In Cocco et al. at first an empirical method is used for assessing 140 buildings of the historic center of Campotosto. Afterwards, a methodology developed at the Padua University is applied to a building compound, representative of the entire buildings stock. Damage probability matrixes and fragility curves are shown and commented, and derived from the damage distribution of the sample considered. The authors confirm that, in the cases analyzed, the damage distribution may be well-predicted with a binomial probability function.

Particular attention to masonry churches is paid in Fabbrocino et al. The results of a preliminary seismic risk assessment of two territorial cases, affected by recent earthquakes occurred in Italy, are 
shown in detail obtained with a new simplified method. This method provides a global resulting score to be used for numerical comparisons at a territorial scale. It may be easily implemented in the multi-level approach proposed within the current Italian Directive for evaluating and mitigating the seismic risk of cultural heritage.

In D'Amato et al. (a) this multi-level approach is applied to five masonry churches, belonging to the historical center "Sassi of Matera," a site protected by UNESCO having a moderate seismic hazard. The obtained results are also compared with the new simplified fast appraisal method suitable for territorial evaluations developed at the Basilicata University (Italy). Also, the second level of evaluation implying a macroelement approach is used. The authors point out that simpler methods may overestimate the actual seismic performance of a church.

Particular emphasis to the construction knowledge for a realistic seismic assessment is given in the paper submitted by Caprili and Puncello, where a multidisciplinary and multilevel knowledge procedure is proposed for providing a geometrical-structural model of a building for further numerical investigations. In the paper, four historical masonry cases study are considered and all are located in the Tuscany region.

A retrofitting design of an existing masonry building is conducted in Maraveas, where two different interventions are discussed to seismically retrofit a case study: by considering rigid diaphragms, or external bonding of timber walls with infilled masonry. Linear models are implemented with static and time history analyses, demonstrating the effectiveness of the interventions considered.

In two works, particular attention is paid to ancient masonry towers. Precisely, in Formisano and Milani, a series of nonlinear static pushover analyses are performed by considering a tower independent on the adjacent ecclesiastic aggregate. Then, it is also investigated the entire compound including both the ecclesiastic complex and the tower. The authors conclude that the interaction reduces the seismic vulnerability of more than $20 \%$. Benefits of some interventions are evaluated with pushover analyses, such as: the application of G-FRP sheets or reinforced plaster, both with the confinement of existing openings with steel frames. Whereas, in Ferrante et al. a tower is modeled with the Discrete Element Method, assuming rigid blocks and frictional joints. The dynamic behavior and influence of the inclined configuration is investigated with non-linear analyses, considering recorded seismic excitations. The investigations performed highlights that the tower inclination considerably increases its seismic vulnerability, demonstrated by greater values of displacements and energy dissipation in the inclined shape.

As for R.C. structures, in the paper of Miano et al. the seismic vulnerability of a case study is examined, resulting unsafe under both vertical and seismic loads. In the paper a rational approach to design the interventions is followed, with both on linear and non-linear dynamic analyses. The structural interventions effectiveness is measured coherently with the new Italian guidelines for seismic risk classification of constructions. A different interventions design strategy is followed in D'Amato et al., (b) where the seismic isolation is applied to a building, falling within a high seismic hazard area. The building, designed only for vertical loads without any specific regulation for lateral loads and reinforced with smooth bars, is retrofitted with a seismic isolation system composed by elastomeric and sliding isolators. A new methodology is also proposed for quickly evaluating the seismic capacity of the building by using the GMs recorded in the surrounding area during the 1980 Irpinia earthquake together with attenuation laws.

Pushover analyses are performed in Milosevic et al. to estimate the behavior factor of a particular type of mixed masonryreinforced concrete buildings. The seismic response is evaluated with non-linear pushover analyses, considering both aleatory and epistemic uncertainties. From numerical investigations the behavior factor values result low due to the connection with the structural walls, and in accordance with the ones proposed in most recent seismic codes. Anyway, the authors recommend of carefully assessing the correct value to be assigned, since it highly depends on the specific typology of mixed buildings considered.

Finally, in Casamassima and D'Amato, the fatigue assessment is treated with particular attention to the existing masonry arches bridge. In this way their remaining service life, with possible traffic load limitations, may be estimated. In the manuscript a review of the state-of-the art about recent published fatigue models, also accounting for deterioration effects under cyclic loads is presented. Then, the results related to fatigue performance of a bridge are discussed. A comparison among different existing fatigue models demonstrate that, to date, their application may lead to opposite results. Therefore, appropriate stress-life curves for ancient masonry elements should be determined and implemented in order to evaluate the remaining service life with respect to the cyclic loads.

In conclusion, the studies presented show that it is impossible to generalize the investigations and interventions procedures. This is due to the fact that particular attention must be paid not only to the building typology investigated but also to its evolution through time with construction details. Finally, guidelines agree on applying reversible interventions that may be substituted in the future guaranteeing seismic protection for frequent earthquakes.

\section{AUTHOR CONTRIBUTIONS}

All authors listed have made a substantial, direct and intellectual contribution to the work, and approved it for publication.

Conflict of Interest: The authors declare that the research was conducted in the absence of any commercial or financial relationships that could be construed as a potential conflict of interest.

Copyright (C) 2020 Formisano and D'Amato. This is an open-access article distributed under the terms of the Creative Commons Attribution License (CC BY). The use, distribution or reproduction in other forums is permitted, provided the original author(s) and the copyright owner(s) are credited and that the original publication in this journal is cited, in accordance with accepted academic practice. No use, distribution or reproduction is permitted which does not comply with these terms. 